\title{
Dayside magnetopause transients correlated with changes of the magnetosheath magnetic field orientation
}

\author{
O. Tkachenko ${ }^{1}$, J. Šafránková ${ }^{1}$, Z. Němeček ${ }^{1}$, and D. G. Sibeck ${ }^{2}$ \\ ${ }^{1}$ Charles University, Faculty of Mathematics and Physics, V Holesovickach 2, 18000 Praha 8, Czech Republic \\ ${ }^{2}$ NASA Goddard Flight Center, Greenbelt, MD 20771, USA
}

Received: 22 September 2010 - Revised: 10 February 2011 - Accepted: 9 March 2011 - Published: 19 April 2011

\begin{abstract}
The paper analyses one long-term pass (26 August 2007) of the THEMIS spacecraft across the dayside low-latitude magnetopause. THEMIS B, serving partly as a magnetosheath monitor, observed several changes of the magnetic field that were accompanied by dynamic changes of the magnetopause location and/or the structure of magnetopause layers observed by THEMIS C, D, and E, whereas THEMIS A scanned the inner magnetosphere. We discuss the plasma and the magnetic field data with motivation to identify sources of observed quasiperiodic plasma transients. Such events at the magnetopause are usually attributed to pressure pulses coming from the solar wind, foreshock fluctuations, flux transfer events or surface waves. The presented transient events differ in nature (the magnetopause surface deformation, the low-latitude boundary layer thickening, the crossing of the reconnection site), but we found that all of them are associated with changes of the magnetosheath magnetic field orientation and with enhancements or depressions of the plasma density. Since these features are not observed in the data of upstream monitors, the study emphasizes the role of magnetosheath fluctuations in the solar wind-magnetosphere coupling.
\end{abstract}

Keywords. Magnetospheric physics (Magnetopause, cusp, and boundary layers; Magnetosheath; Magnetospheric configuration and dynamics)

\section{Introduction}

Quasiperiodic fluctuations of magnetic field and plasma parameters at the magnetopause are often attributed to flux transfer events (FTEs), surface waves or recurrent pressure pulses coming from the solar wind or from the foreshock.

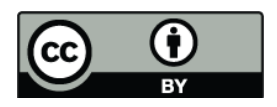

Correspondence to: J. Šafránková (jana.safrankova@mff.cuni.cz)
FTEs were identified in the dayside magnetopause by the ISEE 1 and 2 (Russell and Elphic, 1978, 1979) and by HEOS 2 spacecraft (Haerendel et al., 1978) as a regularly occurring magnetic field signature. Their characteristic features are a bipolar oscillation in the boundary normal component of the magnetic field $\left(\boldsymbol{B}_{N}\right)$, mixtures of magnetosheath and magnetospheric plasmas, and either enhancements or craterlike variations of the magnetic field strength at the event centre. Statistical surveys of the occurrence of FTEs showed that they are observed predominantly when the magnetosheath or interplanetary magnetic field (IMF) points southward (e.g., Berchem and Russell, 1984; Rijnbeek et al., 1984; Southwood et al., 1986; Kuo et al., 1995), strongly suggesting an association with the time-dependent magnetic reconnection process that was proposed as fundamental to the coupling of mass and energy between the solar wind and magnetosphere (Dungey, 1961).

Nevertheless, similar characteristic particle and field signatures at the dayside magnetopause were attributed to a magnetopause motion in response to transient changes in the dynamic pressure of the solar wind (e.g., Sibeck et al., 1989; Sibeck, 1990, 1992; Sibeck and Smith, 1992). These authors suggested that the FTE-type signatures could be generated by a pressure pulse causing scanning of different magnetopause layers (low-latitude boundary layer (LLBL), plasma depletion layer (PDL) and magnetosheath) by a particular observing spacecraft. The authors used the typical properties of these layers to predict the signatures and showed that this scenario could explain the features of the crater-type FTEs. Moreover, some statistical studies (e.g., Kawano et al., 1992; Sanny et al., 1996, 2001) of FTE-type signatures showed no significant southward IMF dependence, thus, they provide support for the pressure-pulse interpretation.

Sibeck et al. (2005) considered the properties of FTEs observed by Interball-1 on a statistical basis and they found that events observed on the mid-latitude magnetopause, equatorward of the cusps, exhibit a strong tendency to occur for

Published by Copernicus Publications on behalf of the European Geosciences Union. 


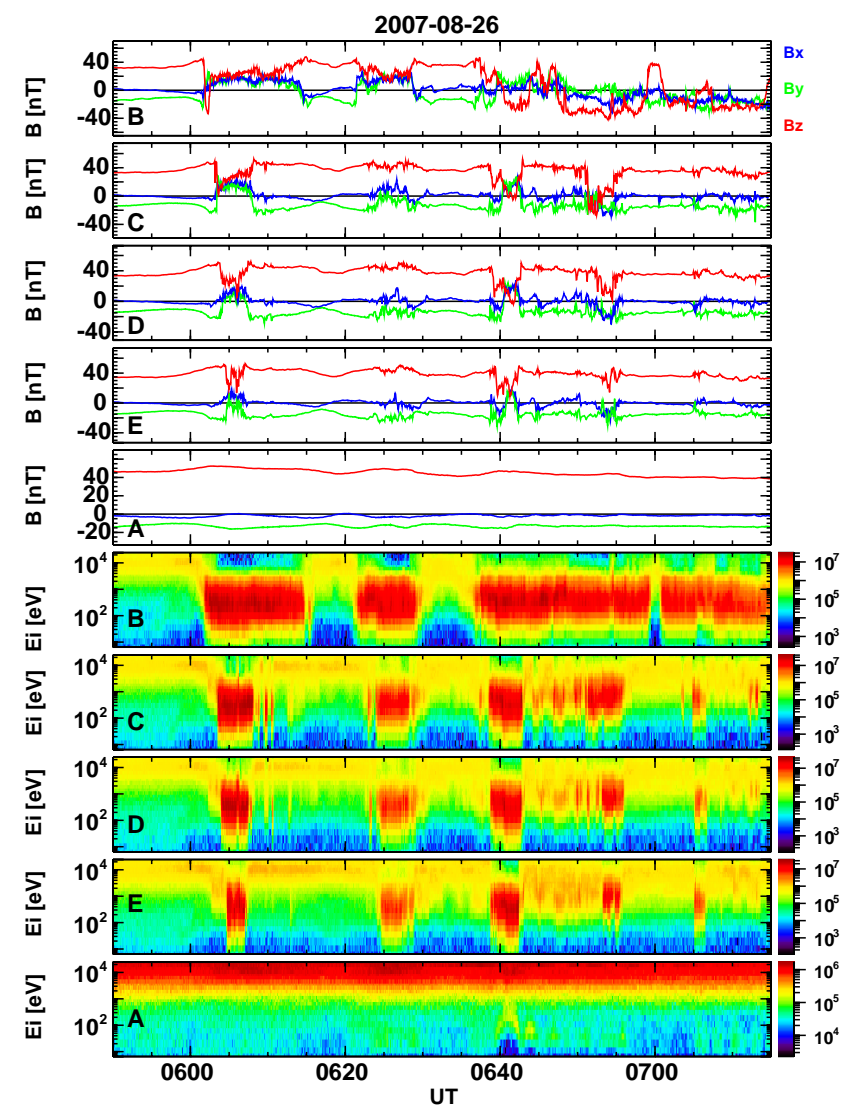

Fig. 1. Overview of THEMIS observations on 26 August 2007 from 05:50 to 07:15 UT. From top to bottom: magnetic fields measured by THB, THC, THD, THE and THA, respectively; ion spectra registered by all THEMIS probes in the same order.

southward magnetosheath magnetic field orientations. By contrast, they further found that events observed at the highlatitude magnetopause, poleward of the cusps, occur for both magnetosheath magnetic field orientations. The authors argue that many of the events observed at the high-latitude magnetopause during intervals of northward magnetosheath magnetic field orientation were actually initiated at previous intervals of southward IMF orientation. They interpreted this result as evidence indicating that events at the high-latitude magnetopause are generated both locally (during periods of northward IMF) and on the equatorial magnetopause (during periods of southward IMF).

An example of magnetopause surface waves excited by the Kelvin-Helmholtz (KH) instability was referred by Eriksson et al. (2009). The authors reported that the trailing (sunward) edges of $\mathrm{KH}$ waves are commonly related to smallscale magnetic islands or FTEs during the growth phase of these surface waves. The authors proposed that these islands were probably generated from a time-varying reconnection process in a low ion plasma beta and low field shear environment at the sunward edge of the growing $\mathrm{KH}$ waves where the local magnetopause current sheet may be compressed by the converging flow of the large-scale plasma vortices as suggested by numerical simulations of the KH instability (e.g., Nykyri and Otto, 2001; Nykyri et al., 2006).

One of the main characteristics of the LLBL is its thickness. Many papers referred to the thick LLBL under northward interplanetary magnetic field (IMF) conditions and the opposite, the thin LLBL under southward IMF (e.g., Mitchell et al., 1987; Lundin, 1988; Wing and Newell, 2002). The other authors also suggested a thick boundary layer during northward pointing IMF (Šafránková et al., 2007; Bogdanova et al., 2008; Rossolenko et al., 2008). Foullon et al. (2008) characterised the evolution of the magnetopause Kelvin-Helmholtz wave activity with changes of the thickness of the LLBL across the dusk flank boundary layer. The authors provided evidence of the contribution of the KelvinHelmholtz mechanism to the widening of the electron LLBL. Their observations were in agreement with the previous statistical study by Mitchell et al. (1987).

In this paper, we present a comprehensive analysis of one pass of the THEMIS spacecraft through the dayside low-latitude magnetopause. During observations, THEMIS registered several quasiperiodic transients characterised by the simultaneous appearance of the magnetosheath or magnetosheath-like plasma at the locations of three or four THEMIS spacecraft. The careful analysis of these transients revealed a different nature of particular events (magnetopause surface deformation, LLBL thickening, pulsed reconnection). None of these events exhibits FTE characteristics (bipolar magnetic field structure), but were found to be a consequence of the changes of the magnetosheath magnetic field $B_{\mathrm{Z}}$ component.

\section{Overview of Themis observations and solar wind conditions}

We used a fleet of the THEMIS spacecraft launched into a near-equatorial orbit on 17 February 2007 (Angelopoulos, 2008). All five spacecraft were aligned across the low-latitude magnetopause and the adjacent layers twice a day with short-time lags between the spacecraft before a modification of their orbits at the end of 2007. Each THEMIS spacecraft carries an identical instrumentation including a fluxgate magnetometer (FGM), an electrostatic analyser (ESA), a solid state telescope (SST), a search coil magnetometer (SCM) and an electric field instrument (EFI). In our analysis, we used magnetic field measurements provided by the FGM instrument (Auster et al., 2008) and plasma measurements of the ESA spectrometer (McFadden et al., 2008). For our investigation of magnetopause transients, we chose a series of magnetopause crossings from the plasma sheet to the magnetosheath, lasting for an hour, that were identified on 26 August 2007. An overview of five spacecraft observations of magnetic fields and ion spectra is 


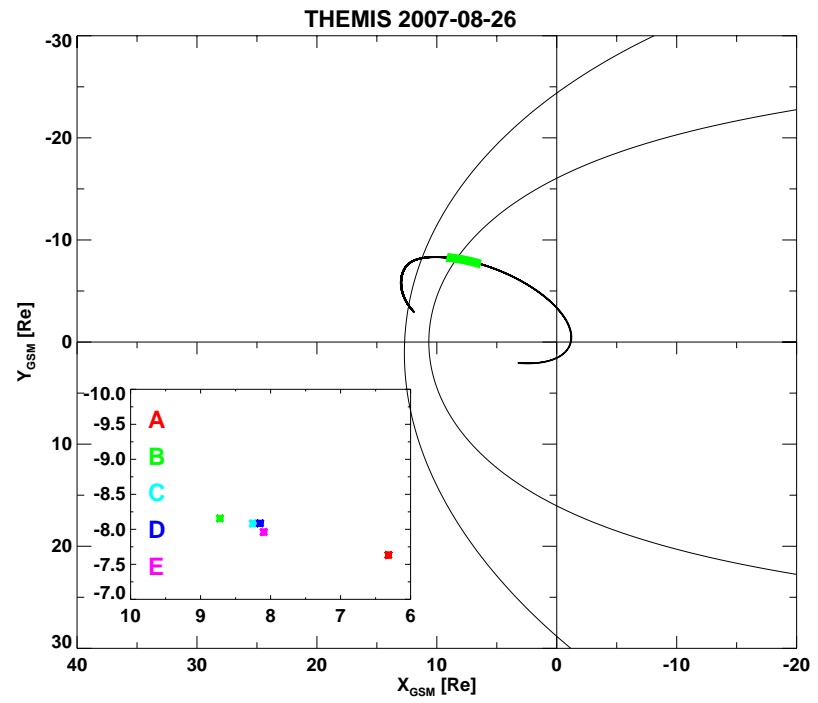

Fig. 2. Projections of THEMIS spacecraft orbits onto the equatorial plane with nominal locations of the bow shock (Jerab et al., 2005) and the magnetopause (Shue et al., 1998). An enlarged view of THEMIS separations is inserted into the bottom part of the figure.

plotted in Fig. 1. A location of the THEMIS spacecraft is displayed in Fig. 2. The spacecraft moved outward along similar orbits. The THEMIS fleet was lead by THB; while THC, THD, and THE were close to each other; and finally, THA followed them with a separation of about $1 R_{\mathrm{E}}$, as can be seen from the insert in the bottom part of the figure. The radial distances of the spacecraft from the Earth were: $\mathrm{THB}=12.81 ; \mathrm{THC}=12.5 ; \mathrm{THD}=12.44 ; \mathrm{THE}=12.34 ;$ and $\mathrm{THA}=11.17 R_{\mathrm{E}}$, respectively at 07:00 UT.

To analyse such observations, an actual IMF orientation is significant. We could use two possible upstream monitors, Wind and ACE, but both of them were located relatively far away from the Sun-Earth line. Unfortunately, other spacecraft that could have been used as solar wind monitors (e.g., Geotail, Cluster) were located in the magnetosphere.

Figure 3 shows a survey of measurements of both solar wind monitors (dynamic pressures, $p$ and $v_{\mathrm{X}}$ components in the 5th and 6th panels, respectively) and IMF (2nd and 3 th panels) propagated to the THB location. However, the separation between ACE $\left(X_{\mathrm{GSE}}=235 R_{\mathrm{E}} ; Y_{\mathrm{GSE}}=39 R_{\mathrm{E}}\right.$; $\left.Z_{\mathrm{GSE}}=-3 R_{\mathrm{E}}\right)$ and Wind $\left(X_{\mathrm{GSE}}=208 R_{\mathrm{E}} ; Y_{\mathrm{GSE}}=-85 R_{\mathrm{E}}\right.$; $Z_{\mathrm{GSE}}=-10 R_{\mathrm{E}}$ ) along the $Y_{\mathrm{GSE}}$ axis was $\approx 125 R_{\mathrm{E}}$. This is of the order of a correlation length of solar wind features in the direction perpendicular to the solar wind velocity (Richardson and Paularena, 2001), thus, it is not surprising that the observations of both monitors differ substantially. To verify our propagation algorithm, we added solar wind and IMF parameters calculated by OMNI (King and Papitashvili, 2005).

Nevertheless, despite some differences, one can note several common features in observations of all monitors. The

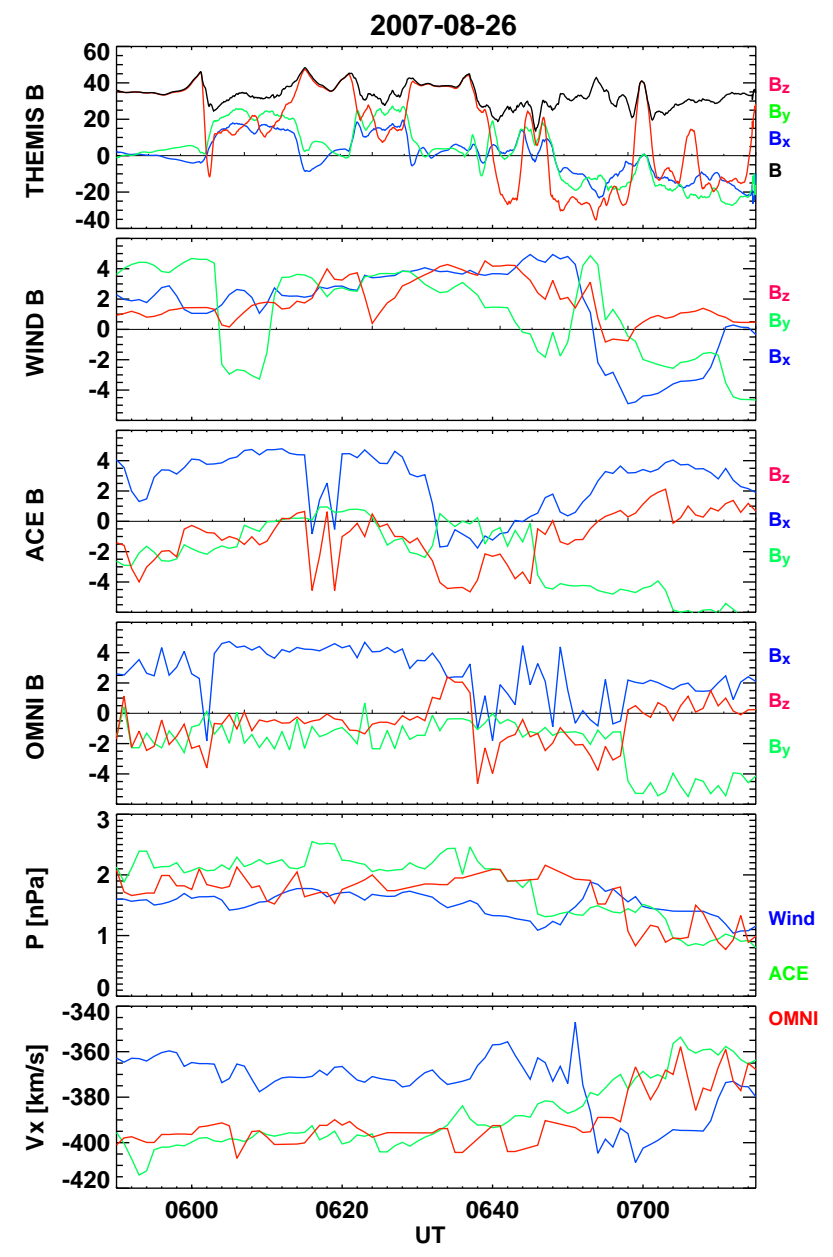

Fig. 3. Measurements of solar wind monitors in the investigated time interval; from top to bottom: the magnetic field from THEMIS $\mathrm{B}$ as a reference; Wind, ACE and OMNI, respectively [in nT]; the solar wind dynamic pressure measured by Wind, ACE and OMNI; and the $v_{\mathrm{X}}$ components registered by Wind, ACE and OMNI, respectively.

solar wind dynamic pressure was almost constant, but different at the positions of both monitors $(2.2-1.5 \mathrm{nPa})$ until $\approx 06: 40$ UT; after this time, it gradually decreased (Wind and $\mathrm{ACE}$ ) and from 07:00 UT, it is again nearly constant with the value of $\approx 1 \mathrm{nPa}$ in data of both monitors. The different values of the solar wind dynamic pressure on ACE and Wind at the beginning of the interval are probably due to various solar wind speeds recorded by the spacecraft ( $v_{\mathrm{X}}$ velocity components are: $-360 \mathrm{~km} \mathrm{~s}^{-1}$ on Wind vs. $-400 \mathrm{~km} \mathrm{~s}^{-1}$ on ACE).

The decrease of the solar wind dynamic pressure leads to an expansion of the magnetopause that follows the outbound motion of THEMIS and, thus, the magnetopause remains approximately between THA and THB.

A similar situation is in the IMF measurements; Wind (second panel) and ACE (third panel) IMF $B_{\mathrm{Z}}$ nearly changes in the anti-phase and significant differences can be found in 


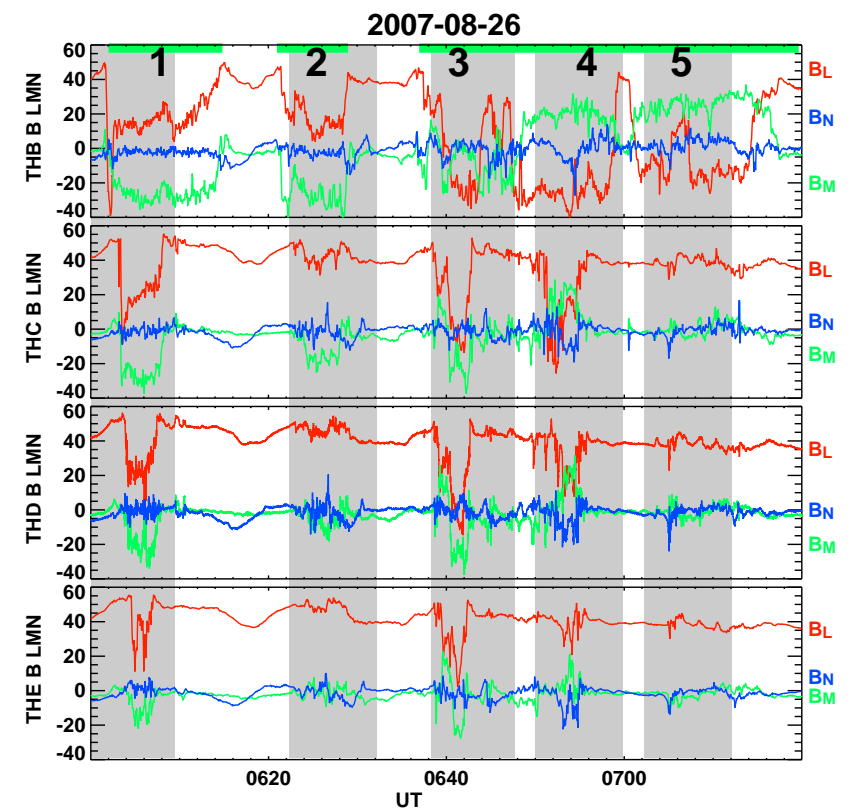

Fig. 4. Magnetic fields [in $n T]$ of THB, THC, THD and THE in the LMN coordinate system at the time interval from 06:00 to 07:20 UT. The discussed events are numbered and the green bars mark intervals when THB was located in the magnetosheath.

other magnetic field components. Since the investigated processes would be determined by the magnetic field being at a close proximity to the magnetopause, we will use THB observations whenever it is located in the magnetosheath. This measurement is shown in the top panel of Fig. 3 .

\section{Analysis of particular events}

As we already pointed out, THA was in the magnetosphere and did not observe notable variations of plasma and magnetic field. For this reason, we are showing only data of THB, THC, THD and THE in following plots. Nevertheless, the information that the observed variations are limited to a thin boundary layer $\left(\approx 1 R_{\mathrm{E}}\right)$ is important for an interpretation.

The original idea behind this analysis was an investigation of FTE properties, so we have recalculated THEMIS magnetic fields into boundary normal coordinates. An interesting result is shown in Fig. 4 - none of the strong density enhancements (see also ion spectra in Fig. 1) possess the most typical FTE characteristics - bipolar $B_{N}$ signature. THEMIS is located near the subsolar point and there is no room for the development of surface waves. Moreover, none of solar wind monitors indicates the changes of the upstream pressure that could be responsible for the observed transients. Furthermore, IMF observations as well as THB measurements in the magnetosheath do not indicate the presence of a strong foreshock in front of the THEMIS spacecraft. For these reasons, we have selected the five most distinct events in a search for

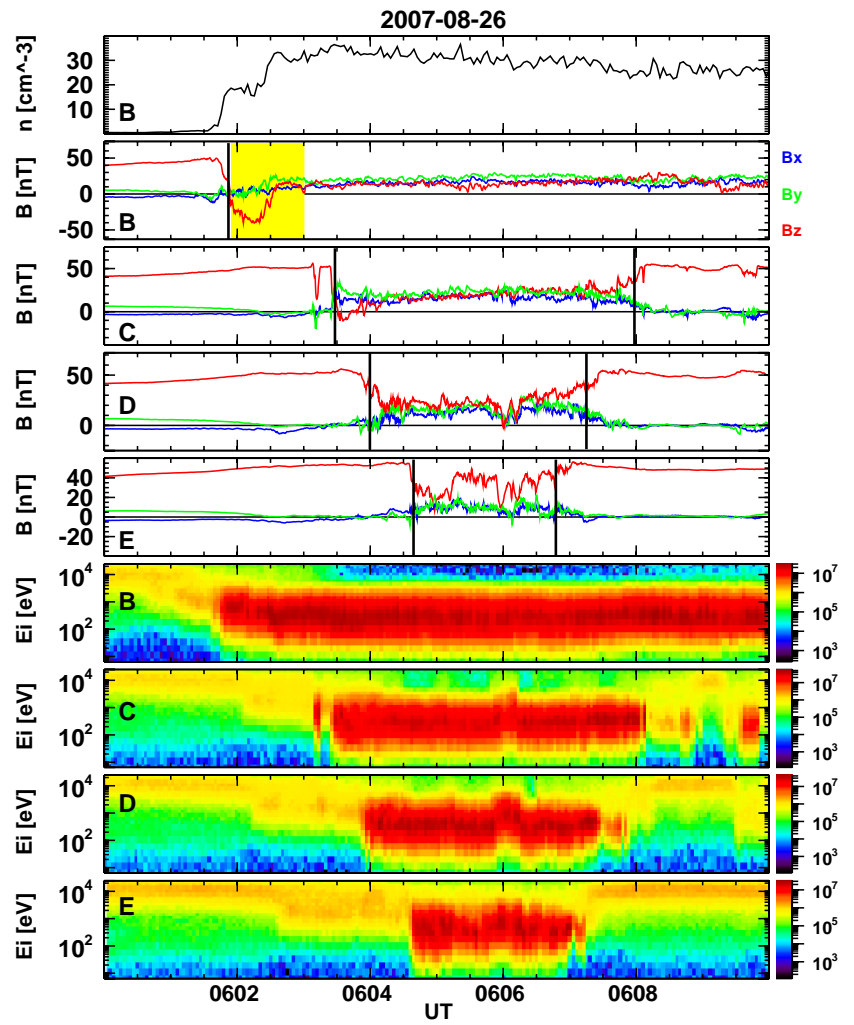

Fig. 5. The density, $n$ from THB, the magnetic field (in GSM) and ion energy spectra measured by THB, THC, THD and THE through the event 1, i.e., from 06:00 to 06:10 UT. The vertical bars indicate estimated magnetopause crossings. The yellow area marks an interval of the discussed change of the $B_{\mathrm{Z}}$ magnetosheath magnetic field orientation.

the sources of the particular transients. The events are numbered from 1 to 5 and distinguished with a grey background in Fig. 4. The heavy green bars at the top of the figure indicate the intervals when THB was located in the magnetosheath and one can note that such observations are available (fully or partly) for all distinguished events.

\section{Event 1: 06:00-06:10 UT}

The magnetic field (in the GSM coordinate system) and ion energy spectra from four THEMIS are plotted in Fig. 5 for the time interval from 06:00 to 06:10 UT. The spacecraft moved in the magnetosphere until 06:02 UT when THB crossed the magnetopause to the magnetosheath and remained there for the rest of the interval. The magnetopause crossing can be undoubtedly identified because it is distinguished by a sharp rotation of the $B_{\mathrm{Z}}$ component from +50 to $-30 \mathrm{nT}$. However, THB $B_{\mathrm{Z}}$ changed again to about $+10 \mathrm{nT}$ about $30 \mathrm{~s}$ later and stood at this level. This fact complicates a precise identification of regions visited by other spacecraft because neither in the magnetosphere nor in the boundary 
layer could negative $B_{\mathrm{Z}}$ be found, whereas positive $B_{\mathrm{Z}}$ is found. For this reason, we plot the projections of ion velocities measured by THC, THD and THE onto the XY- and XZ-planes in Fig. 6. In these plots, the probes move from right to left, and minutes from 06:00 UT are distinguished by the dots at the spacecraft trajectories. The direction and magnitude of the ion velocities (15-s averages) are shown by the green or black bars. The magnetosheath orientations (THB) are shown as the arrows in the left bottom corner of each panel. As it can be seen, the green bars on THC, THD and THE trajectories have the same length and orientation as the THB velocity measurements in the magnetosheath.

Comparing the magnetic fields and velocities measured by THB, THC and THD, we can conclude that the spacecraft underwent a short excursion into the magnetosheath. On the other hand, measurements of THE are a little difficult to interpret. It crossed the magnetopause outbound at 06:04:40 UT and inbound at 06:06:40 UT but it observed a significant enhancement of the $B_{\mathrm{Z}}$ component from 06:05:20 to $06: 06: 00$ UT. Since there is no change of a plasma velocity connected with this enhancement, we interpret it as scanning of the magnetosheath magnetic field profile because the magnetic field pile-up is often observed in front of the dayside magnetopause for positive IMF $B_{\mathrm{Z}}$ (Zwan and Wolf, 1976). The estimated crossings of the magnetopause that are shown by the vertical lines in Fig. 5 exhibit a nested structure. Taking into account the spacecraft locations, such features are consistent either with a temporal compression of the whole magnetopause or with a deformation (indentation) of the magnetopause propagating tailward. The minimum variance analysis provides the normal consistent with the magnetopause deformation on the leading edge of the transient. The changes of the magnetic field and plasma parameters at trailing edges are too smooth to allow us a reliable determination of the magnetopause surface.

A comparison of observations of THC, THD and THE with the density profile measured by THB in the magnetosheath (the top panel in Fig. 5) shows that the proper cause of the magnetopause deformation is the transient enhancement of the magnetosheath density associated with the rotation of $B_{Z}$. A careful analysis of upstream conditions (Fig. 3, OMNI panel) shows a change of IMF $B_{\mathrm{Z}}$ from $\approx-3$ to $-1 \mathrm{nT}$ that is not accompanied by any increase in pressure. It means that the amplification of this small change of IMF $B_{\mathrm{Z}}$ and the creation of the associated density enhancement should be attributed to magnetosheath processes.

The magnetopause velocity derived from the timing of the magnetopause crossings is about $12 \mathrm{~km} \mathrm{~s}^{-1}$ at both edges and we can conclude that the magnetopause character changed from a distinct surface to a broad boundary layer during the event. Calculation of the current sheet thickness leads to a value of $150 \mathrm{~km}$ at the leading edge that is of the order of gyroradius of magnetosheath ions. On the other hand, this sheet is by a factor of 5 thicker at the trailing edge.
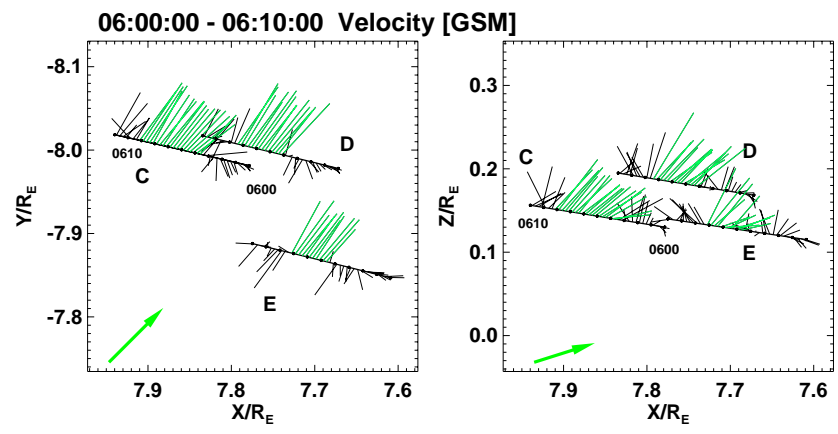

Fig. 6. Projections of ion velocities measured by THC, THD and THE onto the XY- and XZ-planes. The heavy green arrows at the bottom parts of both panels show the velocity directions in the magnetosheath as measured by THB. The spacecraft moves from right to left in the order THC, THD and THE. The green colour indicates estimated magnetosheath intervals.

To demonstrate an evolution of magnetopause layers, we have chosen THD as a representative of the THEMIS fleet and plotted several basic parameters in Fig. 7. The figure presents the electron density, magnetic field in LMN coordinates, electron energy spectrograms and two panels with pitch-angle distributions. The first of them shows the pitchangle distribution of $70-110 \mathrm{eV}$ electrons that can be found in the magnetosheath. The distribution is normalized for better identification of flow directions of these electrons in the regions where they represent a minor population. The second pitch-angle distribution shows boundary layer electrons with higher energies $(200-300 \mathrm{eV})$. The shadowed areas and the dotted vertical lines denote different parts of the boundary layer.

The current sheets are distinguished with the full black vertical lines and we can see that these sheets are occupied with plasma of a magnetosheath origin. The gradual change of the magnetic field orientation from the magnetosheath to that corresponding to a magnetosphere proper at the event trailing edge seems to occur in the magnetosheath because the electron energy spectra and pitch-angle distributions resemble the magnetosheath features. However, we suggest that this region is located on newly reconnected field lines behind the northern cusp. These open lines are still supplied by magnetosheath electrons from the open end of magnetic lines and a portion of these electrons with low pitch angles gradually increases between 06:06:50 and 06:07:20 UT (Onsager et al., 2001; Lavraud et al., 2006; Bogdanova et al., 2008; Øieroset et al., 2008; Li et al., 2009).

On the other hand, an acceleration of particles at the reconnection site should oppose the magnetosheath flow, thus, the particles move only slowly toward the THEMIS location. These particles are seen as a uni-directional flow around 06:07:30 UT in the last panel of Fig. 7. The rest of the boundary layer containing the magnetosheath plasma is observed until 06:07:55 UT. According to pitch-angle distributions, 


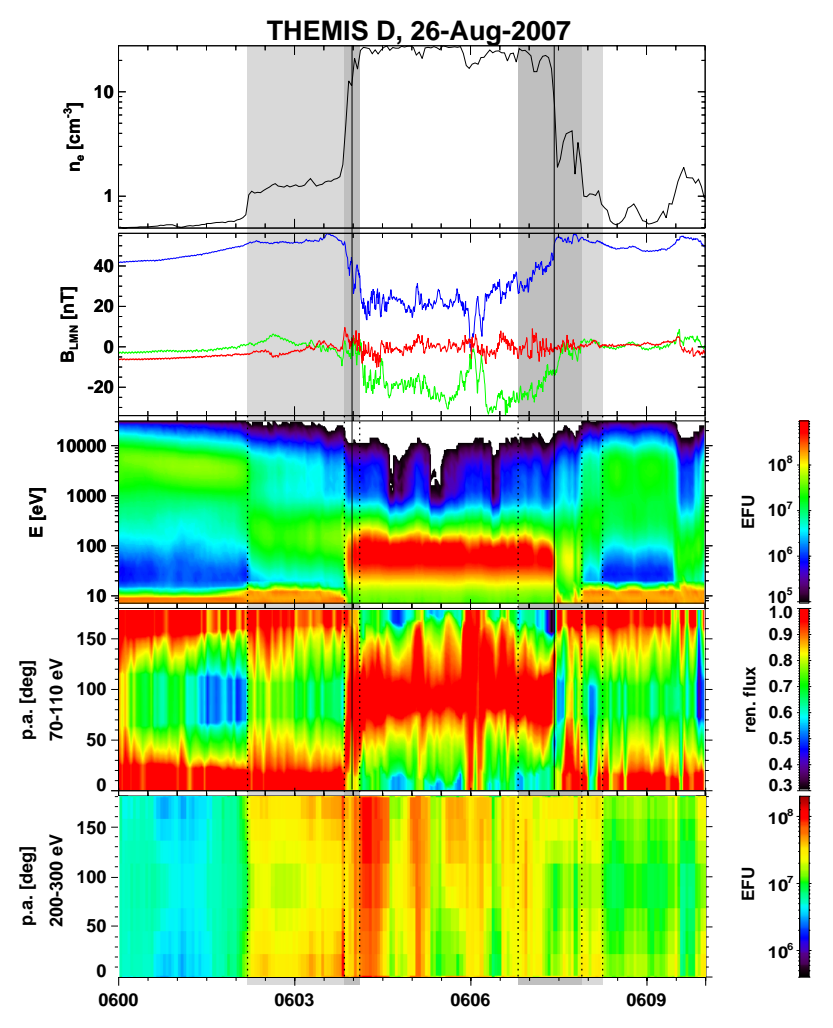

Fig. 7. Event 1. The electron density; the magnetic field in the LMN coordinate system $(\mathrm{L}$ - red; $\mathrm{M}$ - blue; $\mathrm{N}$ - green and magnitude - black); electron energy spectra; the normalized pitch-angle distribution of 70-110 eV electrons; and the pitch-angle distribution of 200-300 eV electrons from the PEER (reduced electron spectra from 6 angles) regime at 06:00-06:10 UT. The dark and slight grey areas denote the outer and inner LLBL, respectively, and the black lines show crossings of the current sheet.

this part of the boundary layer is probably most of the time on the magnetic lines that have been reconnected in the opposite hemisphere, but not necessarily all the time ( $\mathrm{Li}$ et al., 2009).

The structure of the current sheet is rather simple at the leading edge of the event. The pitch-angle distribution changes from the bi-directional streaming that is typical for closed field lines to a very broad distribution. Such a distribution is observed for several seconds and then it changes to the distribution typical for the magnetosheath. These features were registered twice during a magnetic field rotation and we think that this fact can be attributed more likely to small oscillations of the boundary layer than to a bifurcation of the current sheet. We can conclude that a layer of open field lines was not present or it was very thin at the leading edge of the event.

The current sheet is embedded into the LLBL that generally consists of two sub-layers: the outer LLBL that contains magnetosheath like plasma, and the inner LLBL populated by the plasma of lower density and higher tempera-

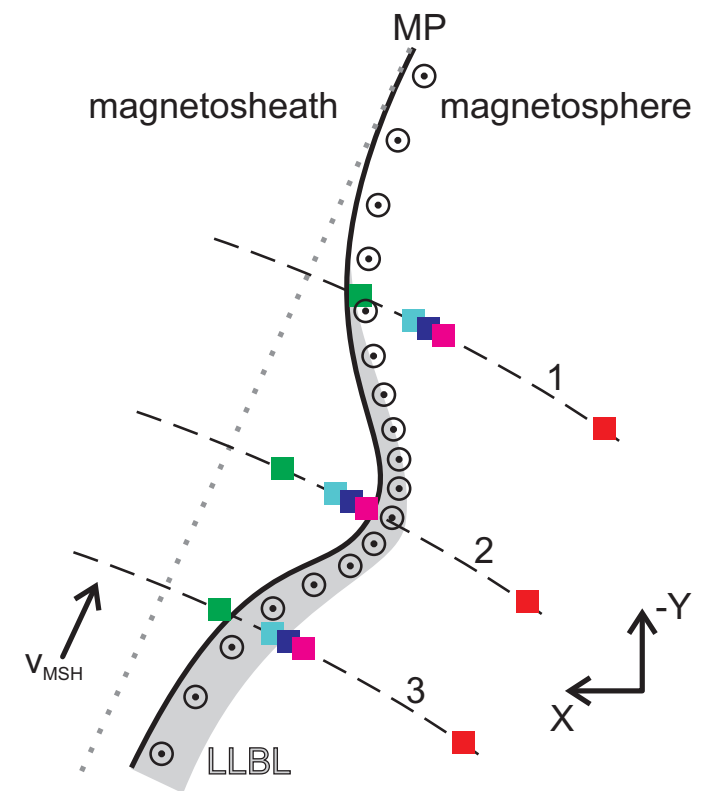

Fig. 8. A schematic drawing of the event 1. The order of THEMIS probes is: THB, THC, THD, THE and THA. The motion of the trough is represented by the motion of the THEMIS fleet in the opposite direction. The location of the spacecraft prior to the event is denoted as 1 and after the event as 3 . $\odot$ represents the magnetic field orientation and its density and the shadowed area stands for an approximate thickness of the outer part of the LLBL.

ture. These layers are distinguished by the dark grey (outer) and light grey (inner) areas in Fig. 7. These layers underwent a significant evolution during the event. Whereas the outer LLBL almost coincides with the current sheet (black lines in Fig. 7) at the leading edge of the event, it is much broader at its trailing edge. On the other hand, the inner part of the LLBL seems to be thinner at the trailing edge. The thickening of the outer LLBL is understandable in terms of dual lobe reconnection induced by northward oriented magnetosheath magnetic field observed by THB. Reconnection enhances the dayside magnetic flux that is transported tailward by the magnetospheric convection and this effect is probably responsible for the decrease of the thickness of the inner LLBL occurring during the event. This mechanism is consistent with a suggestion that the LLBL is thicker during intervals of positive $B_{Z}$ (e.g., Mitchell et al., 1987; Lundin, 1988; Rossolenko et al., 2008) because the authors usually discussed its outer part. We cannot predict the structure and proportions between the outer and inner LLBL parts under steady conditions because Figs. 5-7 show the situation 12 min after the $B_{\mathrm{Z}}$ rotation that is far away from the equilibrium state.

The shape of the magnetopause and adjacent layers during the event, consistent with observation, is schematically shown in Fig. 8. The magnetopause deformation (trough) is oriented along the magnetospheric magnetic field and 


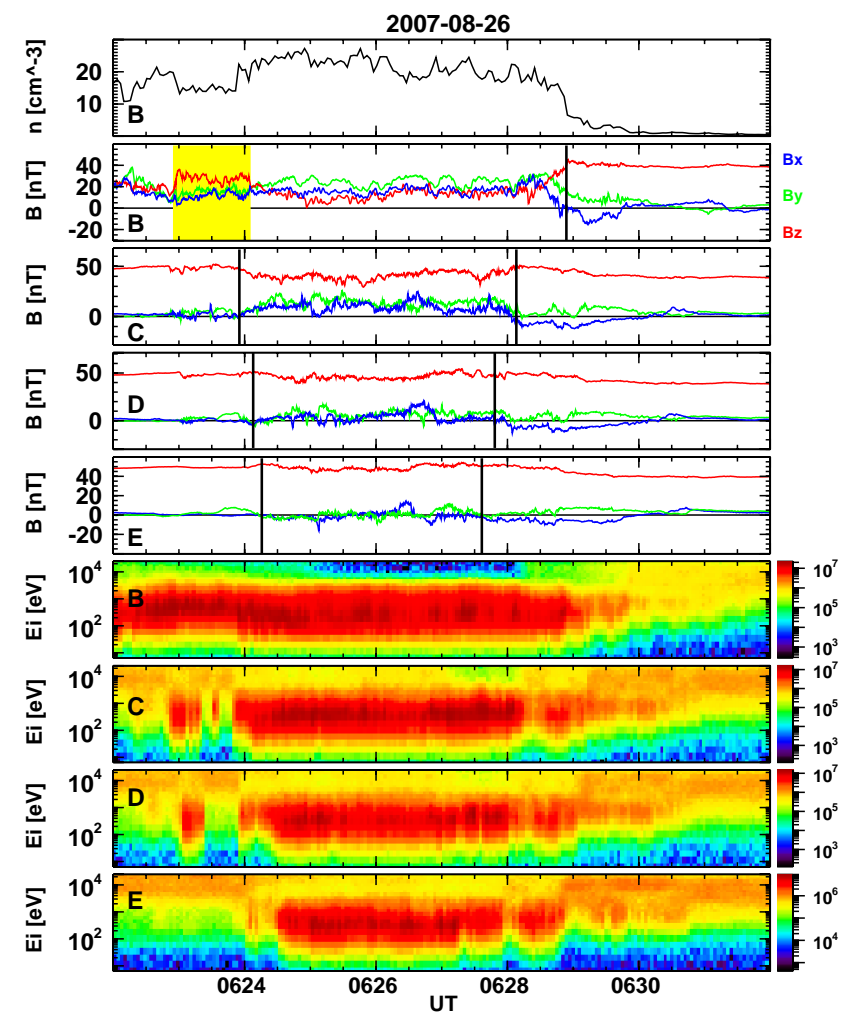

Fig. 9. Overview of the event 2. A detailed view of the density, magnetic fields and ion spectra. The short vertical lines indicate approximate times of sharp changes of the density of low-energy ion population. The yellow area marks an interval of the change of discussed $B_{\mathrm{Z}}$ magnetosheath magnetic field orientation.

proceeds along the magnetopause surface with the magnetosheath speed. In such a case, plasma parameters inside the trough would be identical to those of free-flow magnetosheath. Note that Fig. 8 is not in scale because the deepness of the trough is larger than the separation of THC-THE $\left(\approx 0.2 R_{\mathrm{E}}\right)$, but it is shorter than the separation of THB-THE $\left(\approx 0.6 R_{\mathrm{E}}\right)$. The local time extent of the deformation calculated from the event duration and magnetosheath velocity is $\approx 2 R_{\mathrm{E}}$.

Sibeck et al. (1989); Sibeck $(1990,1992)$ show that magnetopause deformations passing the spacecraft would produce bipolar $B_{N}$ structures similar to those typical for FTEs. However, we argue that the deformation is caused by the pressure enhancement associated with the change of $B_{\mathrm{Z}}$ from strongly negative to positive values. The plane of such magnetic field discontinuity is vertical, the associated region of the enhanced pressure would be highly elongated in the vertical (Z-) direction and the same would hold for the shape of the magnetopause deformation. Such deformation compresses magnetospheric magnetic field lines, but does not change their orientation. Consequently, no changes of the $B_{N}$ component can be expected.

\subsection{Event 2: 06:22-06:32 UT}

Comparing ion energy spectra measured during the first and second events that are shown in Fig. 1, one can note a large degree of similarities. In both cases, all spacecraft except THA observed short-time enhancements of a magnetosheathlike population. However, the magnetic field signatures differ strongly. Whereas during the first event all spacecraft entered the magnetosheath, a blow-up of the second event in Fig. 9 shows a low and variable $B_{\mathrm{Z}}$ component at THB and almost northward pointing magnetic fields at THC, THD and THE. The intervals of observations of the low-energy population are distinguished by the vertical lines. Magnetic field measurements show that three mentioned spacecraft remained on magnetospheric lines during these intervals and entered a boundary layer. The thickening of the LLBL, due to a northward magnetosheath magnetic field, was noted in the previous subsection. The magnetosheath $B_{\mathrm{Z}}$ (observed by THB) remained northward during this event, but its enhancement between 06:23-06:24 UT probably intensifies lobe reconnection and this intensification is a proper cause of the observed transient. The interval of enhanced $B_{\mathrm{Z}}$ is distinguished by the yellow area in Fig. 9 .

Figure 10 presents the electron energy spectra and pitchangle distributions recorded by THD during the event. One can note that the whole region occupied by the magnetosheath-like plasma is probably on open field lines reconnected in the Northern Hemisphere because the distribution is dominated by southward streaming electrons. The density is lower than that in the magnetosheath proper, but Sonnerup et al. (1992) suggested that the LLBL formed in this way exhibits a decreased plasma pressure because a magnetosheath population on open field lines is partly depleted and the diffusion of a hot magnetospheric population onto these magnetic lines is slow. The lack of plasma pressure is replaced with the magnetic pressure as can be seen in Fig. 10, because the magnetic field inside the boundary layer (06:24-06:28 UT) is larger than that in the magnetosphere proper (e.g., 06:31 UT).

The reconnection process locks the magnetosheath plasma on to newly created magnetospheric lines and these lines proceed towards the flanks due to the global magnetospheric convection. Since $B_{\mathrm{Z}}$ was a principal component for one minute only, a bulge occupying a limited range of local times would be created, rather than a continuous layer. Němeček et al. (2003) found that if $B_{Z}$ is small, the LLBL is created on the flanks and cannot be observed in the subsolar region. We think that THB, THD and THE encountered the bulge formed during the interval of $B_{\mathrm{Z}}$ dominant as it propagated along the magnetopause. A schematic drawing is shown in Fig. 11. A thick part of the boundary bulge proceeds tailward and dawnward and crosses the spacecraft locations. Note that plasma parameters in the magnetosheath and in the boundary layer (see the energy spectra in Fig. 9) are nearly identical and it prevents excitation of the surface waves. The event 


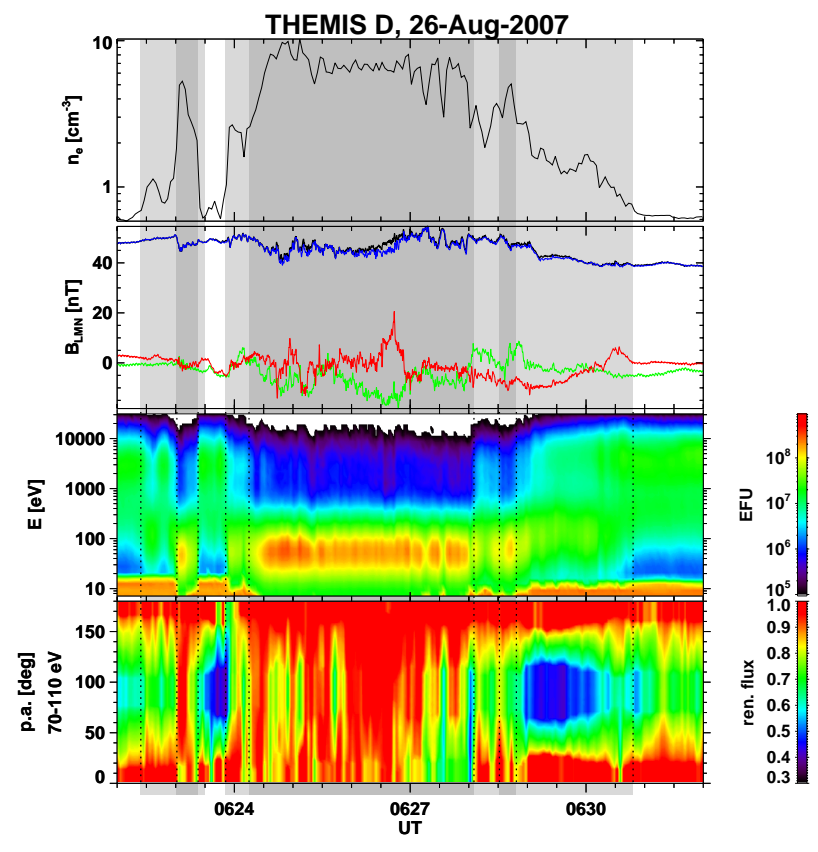

Fig. 10. Event 2. The electron density; the magnetic field in the LMN coordinate system ( $\mathrm{L}$ - red; $\mathrm{M}$ - blue; $\mathrm{N}$ - green and magnitude - black); electron energy spectra; and normalized pitch-angle distribution of 70-110 eV electrons at the 06:22-06:32 UT time interval. The dark and slight grey areas denote the outer and inner LLBL, respectively, and the black lines show crossings of the current sheet.

is terminated at 06:29 UT when THB entered the boundary layer due to the magnetopause outward displacement at this location.

The magnetospheric convection is controlled by the IMF orientation (more precisely, by the orientation of the magnetic field at the magnetopause). A change in direction of the convection velocity recorded by THC-THE at $\approx 06: 29$ UT (not shown) would, thus, be caused by a variation of the orientation of the magnetosheath magnetic field. Moreover, it is clear that such a rotation occurred between 06:29 and 06:40 UT because the magnetosheath magnetic field pointed southward when THB entered the magnetosheath again (Fig. 1). We can conclude that the most probable source of the event termination and THB entering to the magnetosphere is a southward turn of the magnetosheath magnetic field. The southward IMF causes the inward motion of the magnetopause nose and increases its flaring angle. Consequently, a slight outward magnetopause displacement after the southward IMF turn is consistent with the THEMIS location. However, Fig. 9 shows the decrease of the magnetosheath density before 06:29 UT, thus, the outward magnetopause motion can be caused by the decrease of the magnetosheath pressure.

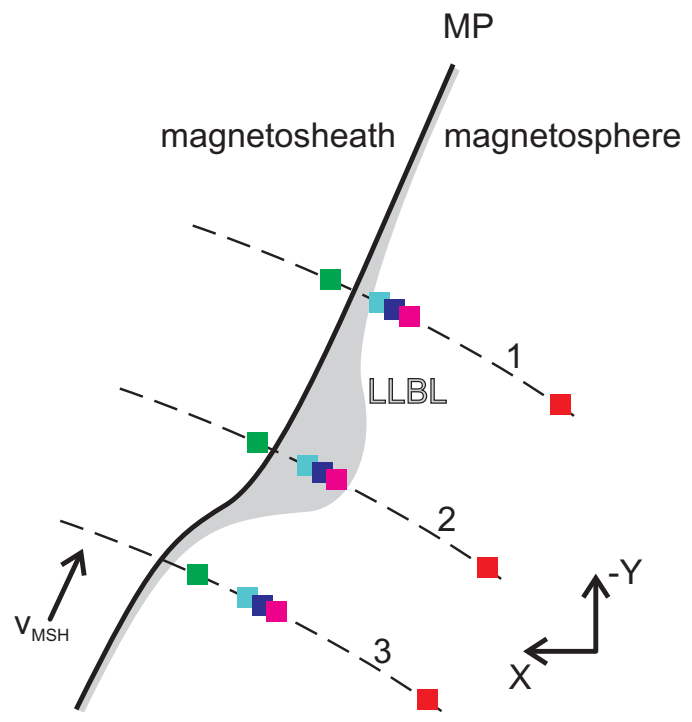

Fig. 11. A schematic drawing of Event 2 showing the thickening of the LLBL due to a change of the $B_{\mathrm{Z}}$ component. The magnetopause motion in time is represented by different THEMIS locations. A shadowed area indicates changing thickness of the outer LLBL.

\subsection{Event 3: 06:38-06:48 UT}

This event is complementary to the event 1 , thus, we comment on it only briefly. As it can be seen in Fig. 4 (note that the $B_{L}$ component is nearly identical with the $B_{\mathrm{Z}}$ GSM component at the THEMIS location), the THEMIS spacecraft sees a compressional increase in the magnetospheric magnetic field strength starting at 06:36UT. This increase probably compensates an enhanced magnetosheath pressure upstream of THEMIS. At 06:38 UT, THB enters the magnetosheath and observed positive $B_{\mathrm{Z}}$. Other spacecraft further register the compressional increase of the magnetospheric magnetic field until $\approx 06: 40$ UT when they visit the magnetosheath and observe a northward magnetosheath field until 06:40:30 UT. THB remained in the magnetosheath for the next $\approx 30 \mathrm{~min}$ and registered a south-north turn of the magnetic field at 06:44 UT. This turn precedes the exiting of other THEMIS spacecraft into the magnetosphere or boundary layer.

We applied an indirect evidence for the estimated increase of the magnetosheath pressure (magnetosheath observations were not available in this time interval) that started the inward magnetopause motion. This inward displacement was probably further enhanced by the magnetopause erosion caused by southward oriented magnetosheath magnetic field within the core of the event. This erosion is terminated by the northward turn of the magnetic field at the magnetopause (THB). Since there is no evidence of a pressure pulse in upstream monitors, we suggest that a proper cause of this transient is a rotation of the magnetosheath $B_{\mathrm{Z}}$ from northward to southward and back, similarly to the first event. 
The north-south turn of magnetosheath magnetic field can be related to a similar rotation seen in OMNI at $\approx 06: 38 \mathrm{UT}$ (see Fig. 3). However, IMF (from OMNI) remained southward oriented after this rotation, whereas the transient was terminated by the south-north turn of the magnetosheath field at 06:43 UT. It means that a possible evolution of IMF from the $\mathrm{L} 1$ point to Earth or the modification of IMF $B_{\mathrm{Z}}$ by magnetosheath fluctuations is a proper cause of the analysed transient. The duration of THB observations of negative $B_{\mathrm{Z}}$ was $\approx 2$ min and the magnetosheath velocity was $\approx 100 \mathrm{~km} \mathrm{~s}^{-1}$. Under frozen-in conditions, the extent of the region with negative $B_{\mathrm{Z}}$ is about $2 R_{\mathrm{E}}$, whereas other parts of the subsolar magnetopause will be affected by the northward pointing magnetic field. It is fully possible that both subsolar and lobe reconnections would act simultaneously under these conditions.

\subsection{Event 4: 06:49-06:59 UT}

During event 4, THB was in the magnetosheath and observed a southward pointing magnetic field with moderate fluctuations (second panel in Fig. 12). Other THEMIS spacecraft started in the magnetosphere and then encountered a region of a depressed magnetic field. The most distinct depression is seen in THC measurements (second panel in Fig. 1), whereas it is rather weak at THE (fourth panel). The magnetic field at THC is oriented mainly southward between 06:51:30 and 06:53:10 UT and we can conclude that the spacecraft is out of the magnetosphere. After 06:53:10 UT, the northward magnetic field indicates that the spacecraft entered the magnetosphere or boundary layer. THD and THC remained through the whole interval in the magnetospheric part of the boundary layer.

Velocity profiles in Fig. 13 reveal a lot of activity in the boundary layer. At quiet times like that at the end of the interval, all velocity components are small. On the other hand, the $v_{\mathrm{Z}}$ component is enlarged at all spacecraft during magnetic field depressions. We marked the time of the change of the THC $B_{Z}$ sign in the corresponding velocity panel by a yellow area and it can be seen that $v_{Z}$ is large and positive when $B_{Z}$ changes its sign. These features are consistent with the crossing of the outflow from a reconnection site located southward of the spacecraft. The strong positive $v_{Z}$ lasts until 06:54:50 UT when $v_{Z}$ changes sign. It can be considered as a motion of the reconnection site to a new location northward of THC. Note that similar changes of $v_{\mathrm{Z}}$ were recorded by THD and THE. The interpretation of such changes as crossings of reconnection outflows is also supported by a test of the Walén relation (Hudson, 1970; Paschmann et al., 1979) that is characterised by the correlation coefficient $R=-0.98$ and by the slope of the regression line of -0.59 . The location of the reconnection site is defined mainly by the magnetosheath magnetic field orientation. In the present case, we have an ideal magnetosheath monitor and we can see that this location is very sensitive to fluctuations of the magne-

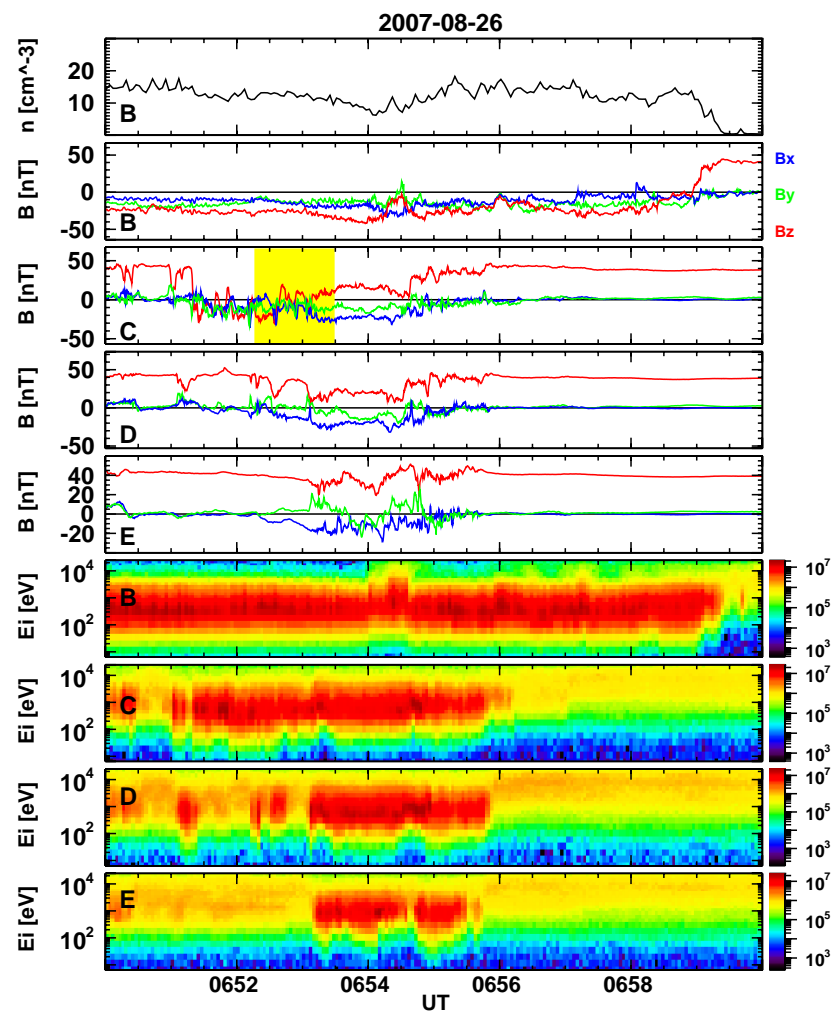

Fig. 12. Overview of Event 4. The same description of the panels as in Fig. 5. The yellow area again marks an interval of the discussed change of the $B_{\mathrm{Z}}$ magnetosheath magnetic field component.

tosheath magnetic field. Its negligible changes (note that the magnetosheath was exceptionally quiet) lead to significant displacements of this site.

\subsection{Event 5: 07:02-07:12 UT}

As seen in Fig. 1, THB was located in the magnetosheath throughout this event. It observed the southward magnetic field that changed to the slightly northward orientation for about one minute (07:05-07:06 UT). This rotation is associated with the appearance of the magnetosheath-like plasma on magnetospheric field lines that was observed by THC, THD and THE. We would like to emphasize that none of the spacecraft crossed the magnetopause, it was located between THB and THC at this time. THC, THD and THE registered the plasma with parameters resembling those of the inner part of the LLBL, thus, the outer part of the LLBL (if there was any) should be very thin and located somewhere between THB and THC prior to and after the event. Consequently, the observation of the outer LLBL by THC, THD and THE during the event can be attributed to a transient thickening of this LLBL part, similarly to Event 2 . The timing of the event shows that the building of the outer part of the LLBL is rather quick and associated with the northward orientation of the magnetosheath magnetic field. Since 


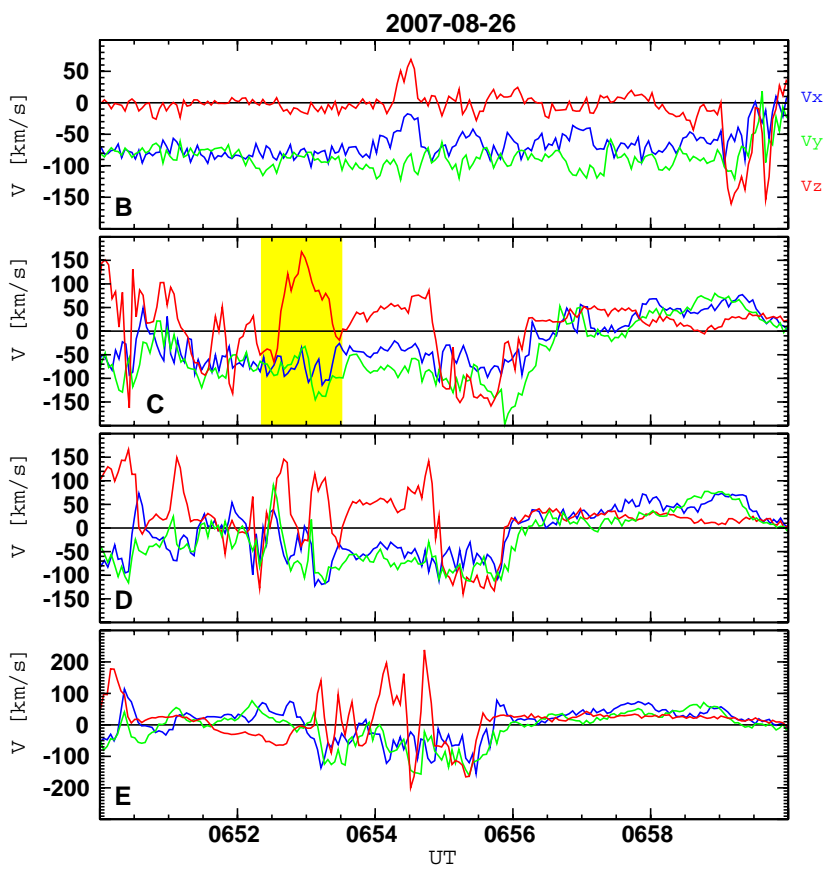

Fig. 13. Velocity profiles of THB, THC, THD and THE during event 4 . The colour of velocity components are: $v_{\mathrm{X}}-$ blue; $v_{\mathrm{Y}}-$ green; $v_{\mathrm{Z}}-$ red. The yellow area marks an interval of the discussed change of $v_{Z}$.

there is no corresponding change in IMF observations (see Fig. 3), the event again demonstrates the importance of magnetosheath fluctuations for the magnetopause processes.

\section{Summary and discussion}

We have analysed in detail several transient events at lowlatitude dayside magnetopause. All events were characterised by short-time enhancements of a low-energy ion population in the data of three THEMIS spacecraft (THC, THD, THE). Although two spacecraft (ACE and Wind) were orbiting in good locations near the L1 point, their data differ significantly and cannot be used for a reliable determination of upstream parameters. However, THB served as a magnetosheath monitor for analysed events, whereas THA located farther inbound did not observe any change. This localizes the events under discussion to a magnetopause boundary layer (LLBL). We have found three types of events, but all of them were accompanied by (and, we believe, caused by) a change of the $B_{\mathrm{Z}}$ magnetosheath magnetic field component.

\subsection{Magnetopause deformation (events 1 and 3)}

$B_{\mathrm{Z}}$ was the principal magnetosheath magnetic field component during these two events and we identified the change of its sign as a source of this magnetopause deformation. However, the mechanisms of creation of the deformation of the magnetopause surface are different in both cases. The event 3 is easy to understand if one admits that a sign of the $B_{\mathrm{Z}} \mathrm{com}$ ponent changes along the magnetopause surface. The part of the magnetopause affected by a southward magnetosheath magnetic field is eroded by reconnection, whereas other parts are not.

On the other hand, the transient and localized inward magnetopause motion observed during Event 1 was associated with both the southward-northward turn of the magnetosheath magnetic field and increase of the plasma density just outbound in the magnetosheath. We suggest that this density enhancement is induced by the magnetic field discontinuity, but the proper cause of the magnetopause deformation is the enhanced magnetosheath pressure.

We have shown that under observed conditions, such deformation does not possess the bipolar signatures suggested by Sibeck et al. (1989); Sibeck $(1990,1992)$ for these type of events. We argue that the deformation highly elongated in the direction of the magnetospheric magnetic field does not produce such signatures (Fig. 8). This elongation was already discussed and it is consistent with the analysis of the boundary normals.

\subsection{Transient LLBL thickening (events 2 and 5)}

A formation of a thick boundary layer during northward pointing IMF (Fig. 11) was suggested by many authors (see e.g., Šafránková et al., 2007; Bogdanova et al., 2008; Rossolenko et al., 2008, and references therein). Moreover, we observed a thickening of this layer during our event 1 (Fig. 8) after a turn of the magnetosheath magnetic field $B_{Z}$ component from negative to positive values. Our event 2 demonstrates that this process is unsteady, especially if the $B_{\mathrm{Z}}$ component of the magnetosheath magnetic field fluctuates. Event 5 demonstrates that the formation (destruction) of a thick boundary layer is very quick when the magnetosheath magnetic field turns northward/southward. Such turns are very frequent in the magnetosheath but observations of induced transients require an appropriate spacecraft constellation in a limited range of local times, thus, they are observed sporadically.

\subsection{Observation of reconnection outflows (even 4)}

We have identified this transient as a crossing of the reconnection outflows. Event 4 clearly shows that a negligible variation of the magnetosheath magnetic field at the magnetopause can change the location of the reconnection site or, maybe, that the reconnection site location is unstable even under steady conditions. The event occurred under a strong southward magnetosheath magnetic field that would imply steady subsolar reconnection or a periodic FTE formation (Russell et al., 1996). The event does not exhibit the FTE features and the multipoint observation allowed us to estimate the thickness of the layer affected by reconnection 
to be $<0.6 R_{\mathrm{E}}$, i.e., significantly smaller than a typical FTE cross-section (Sonnerup et al., 2004). We think that the transient nature of the event is connected with a limited local time extent of the reconnection site. This site then moves not only in the Z-direction (as seen in our data, Fig. 13), but it can shift also in the Y-direction and this shift is responsible for a short-time duration of the observation. Small changes of the orientation of the magnetosheath magnetic field observed by THB are probably the proper cause of this motion.

\section{Conclusion}

The events analysed in the present study exhibit many common characteristics, but they are principally different. The careful analysis revealed that all of them are associated with the change of the magnetosheath magnetic field $B_{\mathrm{Z}}$ component. As Šafránková et al. (2009) have shown, such $B_{Z}$ changes cannot be predicted from observations made far upstream and they are probably a very frequent feature of the dayside magnetosheath. The change of the $B_{\mathrm{Z}}$ component itself was identified as a source of a particular transient, whereas the localized enhancement/depression of the plasma pressure accompanying the $B_{\mathrm{Z}}$ change was a proper cause of the magnetopause deformation in other events. The mutual connection of magnetosheath pressure enhancements and magnetic field rotations can be determined by hybrid simulations that are in under preparation.

Transients connected with a change of the magnetosheath magnetic field $B_{\mathrm{Z}}$ component have several peculiar features that distinguish them from the events of the same kind caused by other sources. We have found that:

1. A monitor of magnetosheath parameters is principal for an interpretation of magnetopause transients.

2. When $B_{Z}$ is the significant magnetosheath component, the magnetopause deformation connected with a change of its sign from southward to northward before the event can lead to a magnetopause deformation similar to that caused by an upstream pressure pulse, but without a bipolar $B_{N}$ signature.

3. The thickness of the boundary layer containing the magnetosheath-like plasma is controlled by the sign of the $B_{\mathrm{Z}}$ component at the magnetopause being thicker for the northward orientation.

4. A short-time enhancement of the northward $B_{Z}$ component creates a bulge of dense low-energy plasma on magnetospheric lines.

Acknowledgements. We acknowledge NASA contract NAS502099 and V. Angelopoulos for use of data from the THEMIS Mission. Specifically, we acknowledge C. W. Carlson and J. P. McFadden for the use of ESA data, K. H. Glassmeier, U. Auster and W. Baumjohann for the use of FGM data provided under the lead of the Technical University of Braunschweig and with financial support through the German Ministry for Economy and Technology and the German Centre for Aviation and Space (DLR) under contract 50 OC 0302 . We also acknowledge ACE, Wind and CDAWeb for the solar wind data. Further, we thank V. Kondratovich for reprocessing the electron spectra and computation of normalized pitch-angle distributions. The present work was partly supported by the Czech Grant Agency under Contracts 205/09/0170, 205/09/0112, and 202/08/H057 and partly by the Research Plan MSM 0021620860 that is financed by the Ministry of Education of the Czech Republic. O. Tkachenko thanks the Charles University Grant Agency (GAUK 163810) for support.

Topical Editor R. Nakamura thanks K. Jacobsen and another anonymous referee for their help in evaluating this paper.

\section{References}

Angelopoulos, V.: The THEMIS mission, Space Sci. Rev., 141, 5, doi:10.1007/s11214-008-9336-1, 2008.

Auster, H. U., Glassmeier, K. H., Magnes, W., Aydogar, O., Baumjohann, W., Constantinescu, D., Fischer, D., Fornacon, K. H., Georgescu, E., Harvey, P., Hillenmaier, O., Kroth, R., Ludlam, M., Narita, Y., Nakamura, R., Okrafka, K., Plaschke, F., Richter, I., Schwarzl, H., Stoll, B., Valavanoglou, A., and Wiedemann, M.: The THEMIS Fluxgate Magnetometer, Space Sci. Rev., 141, 235, doi:10.1007/s11214-008-9365-9, 2008.

Berchem, J. and Russell, C. T.: Flux transfer events on the magnetopause: spatial distribution and controlling factors, J. Geophys. Res., 89, 6689-6703, doi:10.1029/JA089iA08p06689, 1984.

Bogdanova, Y. V., Owen, C. J., Dunlop, M. W., Wild, J. A., Davies, J. A., Lahiff, A. D., Taylor, M. G. G. T., Fazakerley, A. N., Dandouras, I., Carr, C. M., Lucek, E. A., and Reme, H.: Formation of the low-latitude boundary layer and cusp under the northward IMF: Simultaneous observations by Cluster and Double Star, J. Geophys. Res., 113, A07S07, doi:10.1029/2007JA012762, 2008.

Dungey, J. W.: Interplanetary magnetic field and the auroral zones, Phys. Rev. Lett., 6, 47-48, doi:10.1103/PhysRevLett.6.47, 1961.

Eriksson, S., Hasegawa, H., Teh, W.-L., Sonnerup, B. U. O., McFadden, J. P., Glassmeier, K.-H., Le Contel, O., Angelopoulos, V., Cully, C. M., Larson, D. E., Ergun, R. E., Roux, A., and Carlson, C. W.: Magnetic island formation between large-scale flow vortices at an undulating postnoon magnetopause for northward interplanetary magnetic field, J. Geophys. Res., 114, A00C17, doi:10.1029/2008JA013505, 2009.

Foullon, C., Farrugia, C. J., Fazakerley, A. N., Owen, C. J., Gratton, F. T., and Torbert, R. B.: Evolution of Kelvin-Helmholtz activity on the dusk flank magnetopause, J. Geophys. Res., 113, A11203, doi:10.1029/2008JA013175, 2008.

Haerendel, G., Paschman, G., Sckopke, N., Rosenbauer, H., and Hedgecock, P. C.: The frontside boundary layer of the magnetopause and the problem of reconnection, J. Geophys. Res., 83, 3195-3216, 1978.

Hudson, P. D.: Discontinuities in an anisotropic plasma and their identification in the solar wind, Planet. Space Sci., 18, 1611$1622,1970$.

Jeřáb, M., Němeček, Z., Šafránková, J., Jelínek, K., and Merka, J.: A study of bow shock locations, Planet. Space Sci., 53, 85-94, 2005. 
Kawano, H., Kokubun, S., and Takahashi, K.: Survey of transient magnetic field events in the dayside magnetosphere, J. Geophys. Res., 97, 10677-10692, 1992.

King, J. H. and Papitashvili, N. E.: Solar wind spatial scales in and comparisons of hourly Wind and ACE plasma and magnetic field data, J. Geophys. Res., 110, A02104, doi:10.1029/2004JA010649, 2005.

Kuo, H., Russell, C. T., and Le, G.: Statistical studies of flux-transfer events, J. Geophys. Res., 100, 3513-3519, doi:10.1029/94JA02498, 1995.

Lavraud, B., Thomsen, M. F., Lefebvre, B., Schwartz, S. J., Seki, K., Phan, T. D., Wang, Y. L., Fazakerley, A., Reme, H., and Balogh, A.: Evidence for newly closed magnetosheath field lines at the dayside magnetopause under northward IMF, J. Geophys. Res., 111, A05211, doi:10.1029/2005JA011266, 2006.

Li, W., Raeder, J., Oieroset, M., and Phan, T. D.: Cold dense magnetopause boundary layer under northward IMF: Results from THEMIS and MHD simulations, J. Geophys. Res., 114, A00C15, doi:10.1029/2008JA013497, 2009.

Lundin, R.: On the magnetospheric boundary layer and solar wind energy transfer into the magnetopause, Space Sci. Rev., 48(2), 263-320, 1988.

McFadden, J. P., Carlson, C. W., Larson, D., Ludlam, M., Abiad, R., Elliott, B., Turin, P., Marckwordt, M., and Angelopoulos, V.: The THEMIS ESA plasma instrument and in-flight calibration, Space Sci. Rev., 141, 277, doi:10.1007/s11214-008-9440-2, 2008.

Mitchell, D. G., Kutchko, F., Williams, D. J., Eastman, T. E., Frank, L. A., and Russell, C. T.: An extended study of the low-latitude boundary layer on the dawn and dusk flanks of the magnetosphere, J. Geophys. Res., 92(A7), 7394-7404, 1987.

Němeček, Z., Šafránková, J., Přech, L., Šimunek, J., Sauvaud, J.-A., Fedorov, A., Stenuit, H., Fuselier, S. A., Savin, S., Zelenyi, L., and Berchem, J.: Structure of the outer cusp and sources of the cusp precipitation during intervals of a horizontal IMF, J. Geophys. Res., 108(A12), 1420, doi:10.1029/2003JA009916, 2003.

Nykyri, K. and Otto, A.: Plasma transport at the magnetospheric boundary due to reconnection in KelvinHelmholtz vortices, Geophys. Res. Lett., 28, 3565-3568, doi:10.1029/2001GL013239, 2001.

Nykyri, K., Otto, A., Lavraud, B., Mouikis, C., Kistler, L. M., Balogh, A., and Rème, H.: Cluster observations of reconnection due to the Kelvin-Helmholtz instability at the dawnside magnetospheric flank, Ann. Geophys., 24, 2619-2643, doi:10.5194/angeo-24-2619-2006, 2006.

Øieroset, M., Phan, T. D., Angelopoulos, V., Eastwood, J. P., McFadden, J. P., Larson, D., Carlson, C. W., Glassmeier, K. H., Fujimoto, M., and Raeder, J.: THEMIS multispacecraft observations of magnetosheath plasma penetration deep into the dayside low-latitude magnetosphere for northward and strong By IMF, Geophys. Res. Lett., 35, L17S11, doi:10.1029/2008GL033661, 2008

Onsager, T. G., Scudder, J. D., Lockwood, M., and Russell, C. T.: Reconnection at the high-latitude magnetopause during northward interplanetary magnetic field conditions, J. Geophys. Res., 106, 25467-25488, doi:10.1029/2000JA000444, 2001.

Paschmann, G., Papamastorakis, I., Sckopke, N., Haerendel, G., Sonnerup, B. U. O., Bame, S. J., Asbridge, J. R., Gosling, J. T., Russell, C. T., and Elphic, R. C.: Plasma acceleration at the Earth's magnetopause - Evidence for reconnection, Nature, 282,
243-246, 1979.

Richardson, J. D. and Paularena, K. I.: Plasma and magnetic field correlations in the solar wind, J. Geophys. Res., 106(A1), 239251, 2001.

Rijnbeek, R. P., Cowley, S. W. H., Southwood, D. J., and Russell, C. T.: A survey of dayside flux-transfer events observed by ISEE1 and ISEE-2 magnetometers, J. Geophys. Res., 89, 786-800, doi:10.1029/JA089iA02p00786, 1984.

Rossolenko, S. S., Antonova, E. E., Yermolaev, Yu. I., Verigin, M. I., Kirpichev, I. P., and Borodkova, N. L.: Turbulent fluctuations of plasma and magnetic field parameters in the magnetosheath and the low-latitude boundary layer formation: Multisatellite observations on March 2, 1996, Cosmic Research, 46(5), 373-382, 2008.

Russell, C. T. and Elphic, R. C.: Initial ISEE magnetometer results: magnetopause observations, Space Sci. Rev., 22, 681-715, doi:10.1007/BF00212619, 1978.

Russell, C. T. and Elphic, R. C.: ISEE observations of flux transfer events at the dayside magnetopause, Geophys. Res. Lett., 6, 33 36, 1979.

Russell, C. T., Le, G., and Kuo, H.: The occurrence rate of flux transfer, Adv. Space Res., 18, 197-205, doi:10.1016/02731177(95)00965-5, 1996.

Šafránková, J., Němeček, Z., Přech, L., Šimůnek, J., Sibeck, D. G., and Sauvaud, J.-A.: Variations of the flank LLBL thickness as response to the solar wind dynamic pressure and IMF orientation, J. Geophys. Res., 112(A7), A07201, doi:10.1029/2006JA011889, 2007.

Šafránková, J., Hayosh, M., Gutynska, O., Němeček, Z., and Přech, L.: Reliability of prediction of the magnetosheath Bz component from interplanetary magnetic field observations, J. Geophys. Res., 114(A12), A12213, doi:10.1029/2009JA014552, 2009.

Sanny, J., Sibeck, D., Venturini, C., and Russell, C. T.: A statistical study of transient events in the outer dayside magnetosphere, J. Geophys. Res., 103(A3), 4939-4952, 1996.

Sanny, J., Beruhe, D., and Sibeck, D.: A statistical study of transient event motion at geosynchronous orbit, J. Geophys. Res., 106(A10), 21217-21229, 2001.

Shue, J. H., Song, P., Russell, C. T., Steinberg, J. T., Chao, J. K., Zastenker, G., Vaisberg, O. L., Kokubun, S., Singer, H. J., Detman, T. R., and Kawano, H.: Magnetopause location under extreme solar wind conditions, J. Geophys. Res., 103(A8), 17691-17700, 1998.

Sibeck, D. G.: A model for the transient magnetospheric response to sudden solar wind dynamic pressure variations, J. Geophys. Res., 95, 3755-3771, doi:10.1029/JA095iA04p03755, 1990.

Sibeck, D. G.: Transient events in the outer magnetosphere boundary waves or flux-transfer events?, J. Geophys. Res., 97, 4009-4026, doi:10.1029/91JA03017, 1992.

Sibeck, D. G. and Smith, M. F.: Magnetospheric plasma flows associated with boundary waves and flux transfer events, Geophys Res. Lett., 19, 1903-1906, doi:10.1029/92GL01614, 1992.

Sibeck, D. G., Baumjohanann, W., and Lopez, R. E.: Solar wind dynamic variations and transient magnetospheric signatures, Geophys. Res. Lett., 16, 13-16, 1989.

Sibeck, D. G., Korotova, G. I., Petrov, V., Styazhkin, V., and Rosenberg, T. J.: Flux transfer events on the high-latitude magnetopause: Interball-1 observations, Ann. Geophys., 23, 35493559, doi:10.5194/angeo-23-3549-2005, 2005. 
Sonnerup, B., Paschmann, G., Phan, T.-D., and Luhr, H.: Magnetic field maxima in the low latitude boundary layer, Geophys. Res. Lett., 19(17), 1727-1730, 1992.

Sonnerup, B. U. O., Hasegawa, H., and Paschmann, G.: Anatomy of a flux transfer event seen by Cluster, Geophys. Res. Lett., 31, L11803, doi:10.1029/2004GL020134, 2004.

Southwood, D. J., Saunders, M. A., Dunlop, M. W., Mierjedrzejowicz, W. A. C., and Rijnbeek, R. P.: A survey of flux-transfer events recorded by the UKS spacecraft magnetometer, Planet. Space Sci., 34, 1349-1359, doi:10.1016/0032-0633(86)90071-1, 1986.
Wing, S. and Newell, P. T.: 2D plasma sheet ion density and temperature profiles for northward and southward IMF, Geophys. Res. Lett., 29, A1777, doi:10.1029/2002GL015845, 2002.

Zwan, B. J. and Wolf, R. A.: Depletion of the solar wind plasma near a planetary boundary, J. Geophys. Res., 81, 1636-1648, 1976. 